\title{
A Risk Assessment Tool to Predict Sustained PTSD Symptoms Among Women Reporting Abuse
}

\author{
Lene Symes, PhD, John Maddoux, MA, Judith McFarlane, $\mathrm{PrPH}^{1}$, and Jacquelyn Pennings, $\mathrm{PhD}^{2}$
}

\begin{abstract}
Background: Nationally and worldwide, $30 \%$ or more of women are likely to have experienced intimate partner violence. Maternal mental health symptoms predict child function. When mothers have sustained posttraumatic stress disorder (PTSD), their children at are risk for growth and developmental delays and poor behavioral outcomes that may adversely affect the course of their lives. While many who experience trauma will recover without intervention, a significant proportion will experience PTSD, with negative consequences for their personal lives and the lives of their families. Early identification of those at high risk for PTSD symptoms will support early interventions to prevent PTSD and its negative consequences.

Methods: This paper describes the development of a tool that can predict PTSD symptoms at 8 months in mothers who are primarily of low socioeconomic status and primarily members of underrepresented groups. The tool consists of four key measures.

Conclusions: Using this tool to identify mothers at high risk for sustained PTSD and entering them into early intervention programs may protect mothers and their children from negative outcomes and promote their health and wellbeing.
\end{abstract}

\section{Introduction}

$\mathbf{I}$

DENTIFYING SURVIVORS OF TRAUMA who are at risk for chronic posttraumatic stress disorder (PTSD) is a National Institute of Mental Health (NIMH) priority. PTSD risk prediction is important because while many who experience trauma will recover without further intervention, a significant proportion will experience PTSD, with negative consequences for their personal lives and their children's lives. Being able to identify those at high-risk for PTSD will allow researchers to evaluate early interventions to prevent PTSD and its negative consequences. ${ }^{1}$ This paper describes the development and validation of a tool for predicting PTSD symptoms in mothers who are primarily of low socioeconomic status and primarily members of underrepresented groups. This study uses data collected in a 7-year longitudinal study of 300 mother-child dyads.

Nationally and worldwide, $30 \%$ or more of women are likely to have experienced intimate partner violence (IPV)., While many of those women will not experience chronic PTSD symptoms, ${ }^{4,5}$ a substantial number will. Johnson and
Zlotnick, ${ }^{4}$ in a prospective study, found that $46.8 \%$ of 147 residents of a shelter had PTSD symptoms 6 months after seeking assistance, associated with more severe baseline PTSD symptoms and fewer personal and social resources. Similarly, Glass et al. ${ }^{6}$ found that tangible support moderated the relationship between lifetime trauma experience and PTSD $(n=76)$. Ham-Rowbottom et al. ${ }^{7}$ found that of women who were at least 6 months post stays in women's shelters $(n=81)$, more than $70 \%$ had intrusion and avoidance scores indicating clinical levels of PTSD. In their sample, PTSD was associated with family of origin sexual abuse and higher current levels of financial difficulties. Koci et al. ${ }^{8}$ reported that 12 months after seeking a restraining order from a District Attorney's office or safe shelter in a woman's shelter, $39.2 \%$ of women had clinical level PTSD symptom scores.

Maternal mental health symptoms predict child function and therefore when mothers have PTSD their children at are risk for growth and developmental delays and poor behavioral outcomes that may adversely affect the course of their lives. In the 7-year study McFarlane and colleagues ${ }^{9}$ found that of mothers ( $n=300$ mothers and 300 children) who, for

\footnotetext{
${ }^{1}$ College of Nursing, Office of Research and Sponsored Programs, Texas Woman's University, Houston, Texas.

${ }^{2}$ Elite Research, LLC, Carrollton, Texas.

(C) Lene Symes, et al. 2015; Published by Mary Ann Liebert, Inc. This Open Access article is distributed under the terms of the Creative Commons Attribution Noncommercial License (<http://creativecommons.org/licenses/by-nc/4.0/>) which permits any noncommercial use, distribution, and reproduction in any medium, provided the original author(s) and the source are credited.
} 
the first time, sought a protection order through the District Attorney's office or safety at a woman's shelter, those with depression and anxiety were 7 times as likely to have children with similar internalizing problems and mothers with aggression and hostility were 4.5 times as likely to have children with similar externalizing problems. In the same population, 24 months after the mothers sought assistance, data indicates that maternal mental health status remained a strong predictor of child behavioral problems. Maternal PTSD may put children at greater risk of ongoing exposure to violence. In the same sample, PTSD was one of eight risk factors predicting return to the abuser within 24 months of first seeking help. ${ }^{10}$

Panter-Brick et al., ${ }^{11}$ in a study of mother-child dyads living in conflict or refugee settings ( $n=331$ dyads), found that maternal (or prime caregiver) clinical PTSD had the same effect on child function as the child experiencing one or two traumatic events. Enlow et al. ${ }^{12}$ found that maternal PTSD symptoms predicted infants' emotion regulation at 6 months of age. At 13 months of age, by mothers' report, maternal PTSD predicted infant externalizing, internalizing, and dysregulation symptoms. Yehuda and Bierer's ${ }^{13}$ findings suggest that infants of mothers with PTSD may have reduced salivary cortisol beginning in infancy. Identifying those mothers at greatest risk for PTSD and providing early interventions may reduce their children's likelihood of experiencing lifelong problems stemming from their mothers' PTSD symptoms. There is evidence that PTSD can be predicted in individuals who experience trauma. Kessler et al. ${ }^{14}$ conducted analysis of World Health Organization data ( = 47,466 from 24 counties, $4 \%$ positive for Diagnostic and Statistical Manual of Mental Disorders, 4th edition [DSMIV] PTSD) to evaluate how well PTSD can be predicted in those who experience trauma, not limited by type or location. It is noteworthy that $10 \%$ of exposures to traumatic experiences resulted in $95.6 \%$ of the PTSD cases. Individuals with a prior history of PTSD, along with either the experience of having a loved one die unexpectedly or previous sexual trauma, were more likely to have PTSD. Being a woman (odds ratio [OR] 1.5-1.6), experiencing rape (OR 3.2-3.5), childhood physical abuse (1.5-1.8), or being beaten by a spouse/partner (1.5-1.8), and having certain prior lifetime mental health diagnoses including PTSD (27.2) were all associated with increased risk for PTSD. Kessler et al. ${ }^{14}$ noted that $3.5 \%$ of the traumatic experiences were by respondents with prior PTSD and these resulted in $40.5 \%$ of the PTSD diagnoses. They concluded that the findings support the possibility that high-risk individuals can be identified from trauma type and pre-trauma predictors. They also state that "different predictors will almost certainly be found to be important in different populations" (p. 273).

The impact of maternal PTSD on both the mothers and their children indicates a need to identify survivors of abuse who are at risk for PTSD so that intervention can begin, reducing the effects of abuse for mothers and children. Despite the existence of known risk factors for PTSD, we did not identify an existing tool that researchers and front-line social and health professionals can use to predict survivors of partner violence who are most likely to experience PTSD. The purpose of this paper is to describe the development of such a predictive tool using data from a 7-year prospective study of a sample of 300 urban mothers who reported partner violence.

\section{Methods}

\section{Procedure}

Data was collected as part of a 7-year prospective study. Eligibility criteria for the parent study included speaking English or Spanish, having at least one child between the ages of 18 months and 15 years, and seeking partner violence related support for the first time, either through the justice system by applying for a protective order through the district attorney's (DA) office, or through a stay in a safe shelter for abused women. Of the 330 mothers who were eligible to participate, nineteen declined and 11 left the shelter or DA's office prior to contact with researchers. The final sample (Table 1) was 150 mothers from each group. ${ }^{15}$ Following giving informed consent participants were interviewed in a private location by bilingual (Spanish and English) researchers.

\section{Measures}

At each interview, mothers completed a series of measures related to maternal mental health functioning, child behavioral functioning, resiliency factors, and severity of abuse and danger. ${ }^{15}$ To ensure that implementation of the tool is cost effective, only measures (potential predictors) that do not require royalty payments were included in the statistical analysis for the development of the PTSD symptom predictor tool.

Posttraumatic Stress Disorder Symptom Scale. This seven-item symptom scale screens for PTSD. The seven items were empirically derived in an epidemiological study

Table 1. Descriptives of Final Sample

\begin{tabular}{|c|c|c|c|}
\hline & $\mathrm{n}$ & $\%$ & \\
\hline \multicolumn{4}{|l|}{ Group } \\
\hline Shelter & 140 & 48.4 & \\
\hline DA & 149 & 51.6 & \\
\hline \multicolumn{4}{|l|}{ Ethnicity } \\
\hline Non-Hispanic & 112 & 38.8 & \\
\hline Hispanic & 177 & 61.2 & \\
\hline \multicolumn{4}{|l|}{ Immigrant Status } \\
\hline U.S. born & 185 & 36.0 & \\
\hline Immigrant & 104 & 36.0 & \\
\hline \multicolumn{4}{|l|}{ Child gender } \\
\hline Boy & 146 & 50.5 & \\
\hline Girl & 143 & 49.5 & \\
\hline \multicolumn{4}{|l|}{ Education } \\
\hline Less than high school & 95 & 32.9 & \\
\hline High school/GED & 55 & 19.0 & \\
\hline Some college & 121 & 41.9 & \\
\hline \multirow[t]{2}{*}{ College degree } & 18 & 6.2 & \\
\hline & $\mathrm{n}$ & mean & $S D$ \\
\hline Woman's age & 289 & 30.76 & 7.70 \\
\hline Number of people in household & 289 & 3.71 & 1.72 \\
\hline Length of relationship (months) & 289 & 87.07 & 69.25 \\
\hline Number of children & 289 & 1.93 & 1.09 \\
\hline Child age & 287 & 6.89 & 4.23 \\
\hline
\end{tabular}

DA, district attorney's office; SD, standard deviation. 
of PTSD in an urban area. ${ }^{16}$ One item asks, "Do you avoid being reminded of the abuse by staying away from certain places, people, or activities?" Respondents rate each item as "yes" or "no." The score is the sum of the "yes" responses. A score of 4 or more identified cases of PTSD with sensitivity of $78 \%$, specificity of $97 \%$, positive predictive value of $75 \%$, and negative predictive value of $98 \%$. The percentage of correctly classified respondents was $96 \%{ }^{17}$ For this study, PTSD scores were dichotomized based on the critical value of 4 indicating either a positive or negative screen for PTSD.

Safety Behavior Checklist. This seven-item safety survey assesses abused women's present use of safety behaviors and charts future adoption. It was initially published by the March of Dimes ${ }^{18}$ and subsequently updated. ${ }^{19,20}$ Content validity was established. ${ }^{21,22}$ One question is "Have you hidden an extra set of house and car keys?' Depending of the relevance of a given item to a participant, scoring is "adjusted" for purposes of interpretation and comparison. The adjusted total scores range from 0 to 7 , with higher scores indicating higher levels of self-protective behaviors.

Koci Marginality Index (KMI). This five-item Likert scale is an abbreviated version of the KMI-95 and KMI-70. It assesses women's marginality-their perception of living on the periphery of the social center. Women answer five questions with responses from strongly disagree to strongly agree. Scores range from 5 to 25 , with higher scores indicating being more marginalized. One question states, "Meeting new people is hard for me". Internal consistency (Cronbach alpha coefficient) of the KMI-70 was 0.96 $(n=244){ }^{23}$

General Self-Efficacy Scale. This 10-item instrument assesses a general sense of perceived self-efficacy to predict coping and adaptation after stressful life events. Responses to each item are on a four-point scale from 1 (not at all true) to 4 (exactly true). One item is "I am confident that I could deal efficiently with unexpected events." Responses are summed. The possible range of scores is 10 to 40 . Criterion-related validity is well documented. In samples from 23 countries, Cronbach's alphas ranged from 0.76 to 0.90 , with the majority in the high $0.80 \mathrm{~s}^{24}$

Norbeck Social Support Questionnaire. The six-item instrument measures functional properties of social support (e.g., emotional and tangible support) and network properties (e.g., stability of relationships, frequency of contact) and the amount of support from specific sources (e.g., relatives, friends). Respondents indicate the support they perceive from each person on their network list using a five-point rating scale, with a range from 0 for no support through 4 for lot of support. Construct and concurrent validity are established on samples of employed adults. Internal consistency was established with Pearson correlations. ${ }^{25-27}$ After completion of the standard questions, we added a question asking if the abused mother had shared the violence with the individual.

Danger Assessment Scale. This 19-item questionnaire, with a yes/no response format, assesses potential risk for becoming a femicide victim. All items refer to risk factors that have been associated with murder in situations involving abuse. One question is, "Has the physical violence increased in severity or frequency?" Convergent construct validity of the instrument is supported by correlations in the moderately strong range, with instruments measuring severity and/or frequency of abuse. ${ }^{28}$ Validity, in terms of differentiating groups, is supported by the finding of different means in seven groups of women with different histories of abuse. ${ }^{28}$ Initial reliability was $0.71^{29}$ and ranged from 0.60 to 0.86 in five subsequent studies. ${ }^{28}$ Weighted scoring results in four ranges of danger: a score of $<8$ indicates variable danger; $8-$ 13 , increased danger; $14-17$, severe danger; and $\geq 18$, extreme danger.

Severity of violence against women scale. This 47-item instrument measures threats of abuse (19 items) and physical abuse (28 items). Physical abuse items include 6 items on sexual abuse, scored separately. One example of behavior that represents threat is "How often has (name of abuser) threatened to hurt you?' A four-point scale indicates how often the behavior occurred $(1=$ never; 2 , = once; $3=$ two to three times; and $4=$ four or more times). Initial consistency reliability estimates ranged from 0.92 to $0.96{ }^{30}$ Subsequent estimates were 0.89 to 0.91 for threats of abuse and 0.91 to 0.94 for assault. ${ }^{31,32}$ For this study, coefficient alpha was 0.95 for the total scale, 0.90 for Threats of Abuse Subscale, 0.93 for Physical Abuse Subscale, and 0.84 for Sexual Abuse Subscale.

Adverse Childhood Experiences (ACE). The ACE module is a 10-item scale that measures a variety of negative household experiences, including childhood abuse (sexual and physical), domestic violence, and household drug and alcohol abuse. Participants are asked whether they have experienced a particular event as a child. Higher scores indicate a greater number of adverse childhood experiences. ${ }^{33,34}$

\section{Statistical analysis}

A set of potential predictors were selected a priori to be tested to examine if they could significantly predict a positive screen for PTSD at 8 months following entry to the study. The variables chosen were consistent with prior analyses that found links between PTSD severity and severity of abuse, danger for murder, depression, anxiety, social support, and resiliency factors. ${ }^{4}$ The relationship between each predictor variable and clinical levels of PTSD symptoms at 8 months were assessed by univariable categorical regression (Table 2). Continuous variables were modeled using nonmonotonic cubic spline scaling with 4-5 interior knots based on preliminary inspection of receiver operating characteristic (ROC) curve analysis showing nonlinear relationships between the continuous predictors and outcomes. ${ }^{35}$ Beta weights associated with simple nonmonotonic categorical regression are shown in order to provide standardized values that can be assessed as a measure of effect size and to aid in comparison with the continuous variables. Consistent with methods recommended by numerous authors, potential predictors were not eliminated based on the significance level of univariable analysis. ${ }^{36-38}$ Instead, in order to identify the subset of predictors with the highest prognostic ability for long-term PTSD symptoms, categorical regression using optimal scoring and lasso $\left(\mathrm{L}_{1}\right)$ penalization was employed. ${ }^{39}$ 
Table 2. Descriptive Statistics and Bivariate Analyses for Sustained Posttraumatic STRESS Disorder AT EIGHT MONTHS

\begin{tabular}{|c|c|c|c|c|c|c|c|}
\hline & \multicolumn{2}{|c|}{ Negative screen } & \multicolumn{2}{|c|}{ Positive screen } & \multirow[b]{2}{*}{$\mathrm{p}$} & \multirow[b]{2}{*}{ Beta } & \multirow[b]{2}{*}{$\mathrm{p}$} \\
\hline & Mean & $S D$ & Mean & $S D$ & & & \\
\hline ACE total score & 3.97 & 2.81 & 5.21 & 2.53 & $* * *$ & 0.278 & $* * *$ \\
\hline Threats score & 40.15 & 12.95 & 44.18 & 13.39 & $*$ & 0.237 & $* * *$ \\
\hline Physical abuse score & 35.21 & 13.14 & 37.78 & 14.34 & ++ & 0.147 & $* * *$ \\
\hline Sexual abuse score & 8.29 & 3.67 & 8.97 & 4.51 & ++ & 0.165 & $* * *$ \\
\hline Danger assessment & 15.26 & 6.75 & 17.20 & 7.00 & $*$ & 0.145 & $* * *$ \\
\hline Woman's age & 29.91 & 7.54 & 32.06 & 7.80 & $*$ & 0.165 & $* * *$ \\
\hline Emotional support & 3.50 & 0.48 & 3.18 & 0.75 & $* * *$ & 0.198 & $* * *$ \\
\hline Tangible support & 3.20 & 0.79 & 2.99 & 0.90 & $*$ & 0.152 & $* * *$ \\
\hline Support regarding abuse & 3.32 & 1.00 & 3.11 & 1.19 & ++ & 0.124 & $* * *$ \\
\hline Safety behaviors & 3.31 & 1.63 & 3.80 & 1.66 & $*$ & 0.162 & $* * *$ \\
\hline General self-efficacy & 31.78 & 5.98 & 30.04 & 5.77 & $*$ & 0.199 & $* * *$ \\
\hline Marginalization & 12.82 & 5.18 & 13.98 & 5.55 & + & 0.155 & $* * *$ \\
\hline \multirow[t]{2}{*}{ PTSD symptomatology } & 4.54 & 1.87 & 5.97 & 1.40 & $* * *$ & 0.423 & $* * *$ \\
\hline & $\mathrm{n}$ & $\%$ & $\mathrm{n}$ & $\%$ & $\mathrm{p}$ & $B_{e t a}{ }^{a}$ & $\mathrm{p}$ \\
\hline Childhood physical abuse & 60 & 34.5 & 57 & 50.4 & $* *$ & 0.159 & $* * *$ \\
\hline CSA - touched & 61 & 35.1 & 59 & 52.2 & $* *$ & 0.170 & $* * *$ \\
\hline $\mathrm{CSA}$ - forced to touch & 37 & 21.3 & 42 & 37.2 & $* * *$ & 0.174 & $* * *$ \\
\hline
\end{tabular}

Bivariate relationships were assessed linearly (using Mann-Whitney U tests due to non-normal distributions) for continuous variables (shown as median [interquartile range]). For categorical variables, bivariate relationships were assessed using crosstabs with chi-squared tests and are shown as $n(\%)$. Betas are shown for simple categorical regression with nonmonotonic cubic spline scaling with three interior knots for continuous variables, and for categorical variables, nominal dummy coding was used.

${ }^{\dagger} p<0.20,{ }^{\dagger} p<0.10, * p<0.05 ; * * p<0.05, * * * p<0.001$.

ACE, Adverse Childhood Experiences module; CSA, Childhood Sexual Abuse; PTSD, Post-traumatic stress disorder.

$\mathrm{L}_{1}$-penalizing methods shrink the estimates of the regression coefficients toward 0 relative to the maximum likelihood estimates in order to reduce over fitting arising from small samples, collinearity, and high dimensionality. The amount of shrinkage is determined by the tuning parameter $\lambda_{1}$, which is progressively increased to the value that shrinks all regression coefficients to 0 . The least absolute shrinkage and selection method allows assessment of the relevance and robustness of individual explanatory variables but produces biased estimates for the regression coefficients. Therefore, once the optimal selected predictors were obtained using the lasso with 0.632 bootstrap (100 samples), final model coefficients and scoring were conducted using categorical regression with optimal scoring.

Next, standard multiple logistic regression was used to obtain the predicted probability of a positive screen for PTSD at 8 months from the score obtained from combining the set of optimal predictors into a regression equation. Model discrimination was assessed by the area under the curve (AUC) and the discrimination slope. Model calibration was assessed using the Hosmer-Lemeshow test and by assessing the stratification capacity. ${ }^{40}$ Within sample model validation was addressed by bootstrapping the AUC and reporting the values and $95 \%$ confidence interval (CI) along with estimated minimum and maximum values to maximize statistical efficiency. ${ }^{41}$ Out-of-sample validation was conducted by predicting PTSD at 16 months. The stratification capacity of the out-of-sample is reported along with the Hosmer-Lemeshow test and the AUC (with bootstrapping). Analyses were completed using both IMB SPSS version 22 and Medcalc version 13.
Predictors were further examined using CATREG optimization in order to create the most parsimonious predictor tool to account for the greatest amount of significance while being mindful of number of items, scoring simplicity, and availability to reproduce survey items. All 16 predetermined predictor variables were entered into each categorical regression with optimal scoring and lasso $\left(\mathrm{L}_{1}\right)$ penalization. ${ }^{40}$ All predictors were allowed to be nonmonotonic and cubic splines were used for continuous predictors. Knots were placed by the CATREG program in IBM $^{\circledR}$ SPSS $^{\circledR}$ Statistics 21, which uses procedure-determined placement of the interior knots. ${ }^{42}$ The predictors identified in the optimal model (determined by applying interative $\lambda_{1}$ penalizations using 0.632 bootstrap and identifying the iteration with the smallest estimate for the expected prediction error in the standardized data, as described in the methods section) were retained. A second round of modeling was done using the same procedure with only the variables from the optimal model in order to determine if a more parsimonious optimal model could be found. Once a stable set of predictors was established, continuous variables were discretized into groups with uniform distribution in order to create categories that could be scored in a tool developed for front-line providers. The number of categories ranged from four to six based on the number of categories that optimized that $\mathrm{R}^{2}$ of the overall model. The final predictors were then entered into a categorical regression with no penalization. Both the categorical predictors and discretized continuous variables were entered nonmonotonically. Beta weights and the optimal scores for each category of each predictor were multiplied in order to create a regression equation for each model. These 
values were linearly transformed in the final tools in order to eliminate negative values and decimal places $\{[$ (quantification score $\times$ beta) +1$] \times 100\}$.

\section{Results \\ Sample}

Data was collected at baseline and 8 months and 16 months later. A total of $289(96 \%, 140$ shelter; 149 DA) mothers were retained to 16 months. Ages at baseline ranged from 18 to 52 years (mean 30.76; standard deviation 7.70). Over half of the sample identified as Spanish or Hispanic (61.2\%) and 36\% of the sample were immigrants to the United States (Table 1).

\section{Model development}

Preliminary analyses found no differences in the relationships between predictor variables and screening positive for PTSD 8 months following initial contact with service providers across groups (e.g., DA, Shelter), and a single model was developed to create a rapid assessment tool for prolonged PTSD symptomatology. A summary of the simple bivariate relationships and descriptors of key predictors is outlined in Table 2 . As shown, the majority of predictors tested were associated with a positive screen for PTSD at 8 months with significance levels ranging from approaching significance (e.g., $p<0.20)$ to highly significant $(p<0.001)$.

A summary of the final predictors is outlined in Table 3. As shown, the final predictor tool consists of 4 key measures: adverse childhood experiences, emotional support, general self-efficacy, and total PTSD symptom counts at baseline. The final scores after transformation are shown in the final rapid assessment tool (see Fig. 1). Final model beta coefficients and associated model statistics, including the AUC, are presented in Table 3 . The AUC predicting a positive screen for PTSD at 8 months was high (0.804) good model discrimination. After 2000 cycles of bootstrapping, the average reduction in AUC was $0.002(95 \%$ CI change $<0.01)$, suggesting very minimal overfitting. Furthermore, the dis-

Table 3. Model Coefficients and Performance

\begin{tabular}{lccc}
\hline & Beta & SE & $\mathrm{p}$ \\
\hline ACE & 0.20 & 0.05 & $* * *$ \\
Emotional support & 0.16 & 0.05 & $* * *$ \\
General self-efficacy & 0.16 & 0.04 & $* * *$ \\
PTSD symptomatology & 0.34 & 0.06 & $* * *$
\end{tabular}

Model Summary

$\mathrm{F}$

$\mathrm{R}^{2}$

Adjusted $\mathrm{R}^{2}$

$6.65 * * *$

0.271

0.231

Hosmer-Lemeshow chi-squared $(p)$

AUC $(95 \%$ CI)

$4.69(0.790)$

Bootstrap AUC $(95 \% \mathrm{CI})^{\mathrm{a}}$

$0.804(0.751,0.856)$

$0.802(0.748,0.853)$

Coefficients are standardized, estimate of SE (bootstrap 1,000).

${ }^{a}$ Bootstrap sample $=2,000$, random seed. Web program developed by Skalská and Freylich ${ }^{41}$ was used.

$* * * p<0.001$.

AUC, area under the curve; CI, confidence interval; PTSD, posttraumatic stress disorder; SE, standard error of the mean.
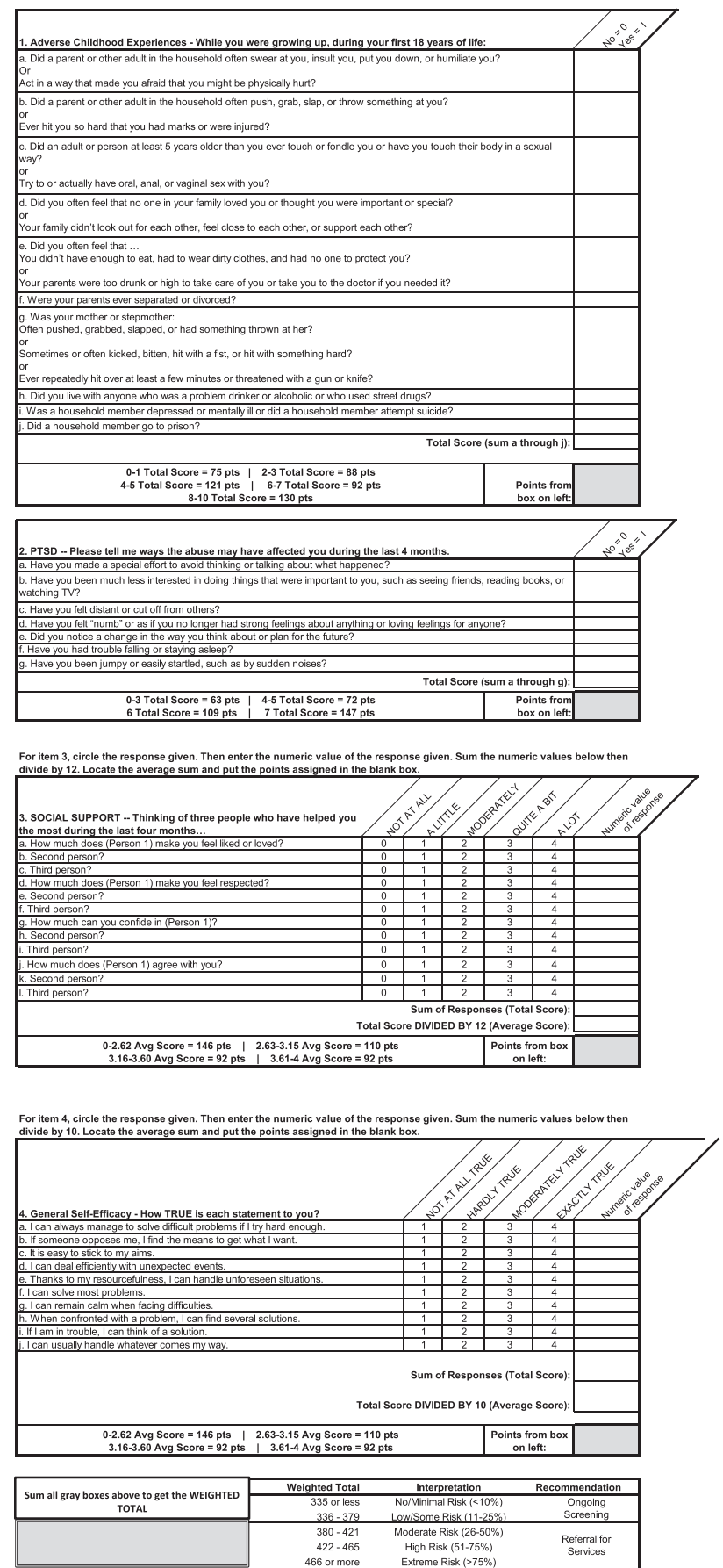

FIG. 1. Rapid Assessment Tool to predict risk for sustained PTSD symptoms.

crimination coefficients, or in other words, the absolute difference in the average prediction for positive and negative PTSD screens at 8 months was $27.3 \%$ (standard error $[\mathrm{SE}]=2.9 \%, p<0.001)$. Mothers with sustained PTSD had significantly higher average predicted probabilities than mothers who did not have clinical level PTSD symptoms.

As shown in Table 4, the final model predicted a positive PTSD screen at 8 months into clinically relevant risk categories, indicating good model calibration. As shown, none of the mothers who had a low predicted probability $(<10 \%)$ had a positive screen for PTSD. Conversely, $91 \%$ of mothers who 
Table 4. Risk Stratification Table Assessing Models by Predicted Probabilities

\begin{tabular}{lcccrc}
\hline Predicted probabilities & $\mathrm{n}(\%)$ & $\begin{array}{c}\text { Positive } \\
\text { screen, } \mathrm{n}(\%)\end{array}$ & $\begin{array}{c}\text { Negative } \\
\text { screen, } \mathrm{n}(\%)\end{array}$ & $\begin{array}{c}\text { Sensitivity } \\
\%(\text { LR+) }\end{array}$ & $\begin{array}{c}\text { Specificity } \\
\%(\text { LR-) }\end{array}$ \\
\hline $\begin{array}{l}8 \text { Months } \\
<10 \%\end{array}$ & $23(8.0 \%)$ & $0(0 \%)$ & $23(100.0 \%)$ & - & - \\
$10 \%-25 \%$ & $79(27.3 \%)$ & $14(17.7 \%)$ & $65(82.3 \%)$ & $100(1.17)$ & $14.29(0)$ \\
$26 \%-50 \%$ & $63(21.8 \%)$ & $23(36.5 \%)$ & $40(63.5 \%)$ & $86.54(1.91)$ & $54.66(1.91)$ \\
$51 \%-75 \%$ & $65(22.5 \%)$ & $38(58.5 \%)$ & $27(41.5 \%)$ & $64.42(3.14)$ & $79.50(.45)$ \\
$>75 \%$ & $35(12.1 \%)$ & $29(82.9 \%)$ & $6(17.1 \%)$ & $27.88(7.48)$ & $96.27(.75)$ \\
16 Months (validation) & & & & \\
$<10 \%$ & $23(8.0 \%)$ & $2(8.7 \%)$ & $21(91.3 \%)$ & - & - \\
$10 \%-25 \%$ & $79(27.3 \%)$ & $9(11.4 \%)$ & $70(88.6 \%)$ & $97.65(1.11)$ & $11.67(.20)$ \\
$26 \%-50 \%$ & $63(21.8 \%)$ & $24(38.1 \%)$ & $39(61.9 \%)$ & $87.06(1.76)$ & $50.56(.26)$ \\
$51 \%-75 \%$ & $65(22.5 \%)$ & $29(44.6 \%)$ & $36(55.4 \%)$ & $58.82(2.12)$ & $72.22(.57)$ \\
$>75 \%$ & $35(12.1 \%)$ & $21(60.0 \%)$ & $14(40.0 \%)$ & $24.71(3.18)$ & $92.22(.82)$ \\
\hline
\end{tabular}

LR+, positive likelihood ratio; LR-, negative likelihood ratio.

were classified as being high risk (predicted probability $>75 \%$ ) had a positive screen for PTSD at 8 months following initial contact.

\section{Model validation}

In order to validate the newly developed rapid assessment tools, obtained predicted probability from the tool were used to predict a positive PTSD screen at 16 months following initial contact. ROC analysis indicated that scores from the developed screening tool could significantly predict a positive PTSD screen at 16 months $(\mathrm{AUC}=0.730, p<0.001)$. Additionally, after 2,000 cycles of bootstrapping, the average reduction in AUC was 0.001 (95\% CI change <0.01), suggesting minimal overfitting of the model. The HosmerLemeshow test demonstrated adequate calibration $\left(\chi^{2}\right.$ $(10)=10.57, p=0.227)$. As also shown in Table 4, only 2 of the 23 mothers classified as low risk (predicted probability $<10 \%$ ) screened positive for PTSD at 16 months following initial contact $(8.7 \%)$. Additionally, $60.0 \%$ of the 35 mothers who were classified into the highest risk category (predicted probability $>75 \%$ ) screened positive for PTSD at 16 months. Overall the validation model suggests excellent sensitivity and specificity for mothers who screen as lower risk (predicted probability of $<10 \%, 10 \%-25 \%$, and $26 \%-50 \%$ ). For mothers who screen higher risk $(51 \%-75 \%$ and $>75 \%)$ the model slightly overestimates the mother's risk of sustained PTSD. Finally, the discrimination coefficient for positive and negative PTSD screens at 16 months was $20.4 \%$ (SE $=3.2 \%$, $p<0.001)$. Mothers with sustained PTSD had significantly higher average predicted probabilities than mothers who did not have clinical level PTSD symptoms.

\section{Scale administration}

Professionals and trained para-professionals can easily administer, score, and interpret the final screening tool (Fig. 1). To administer, each question should be read aloud by the person administering the tool and responses noted and scored on the provided scoring sheet. Within each set of items, scores should be summed or averaged as described, and then interpreted according to the range of weighted values provided. To create a total score, sum the weighted value of each subscale. Recommendations are provided based on total scores.

\section{Results}

This study outlined the development of a new rapidassessment screening tool to predict prolonged PTSD (defined as a positive screen for PTSD 8 months following initial contact with either a shelter or the DAs office) among a sample of mothers seeking abuse-related support for the first time. Additionally, the newly developed tool was validated on the same sample across a different time point, indicating that the rapid assessment tool appears to be capable of accurately predicting long-term PTSD symptoms up to at least 16 months following initial contact with services providers.

\section{Discussion}

The PTSD predictor tool, consisting of 4 scales that can be used without payment, will allow for the assessment of mothers when they first seek assistance for intimate partner violence. Once identified those at greatest risk for clinical level PTSD symptoms many months after the trauma can be referred for intervention to prevent or treat PTSD. This tool contributes to meeting the need identified by the $\mathrm{NIMH}^{1}$ to identify survivors of trauma at greatest risk for sustained PTSD.

While the participants of this study were a group of mothers who sought assistance for intimate partner violence for the first time it is likely that this predictor tool may be useful in other populations, for instance those who are identified through screenings rather than self-identified, and in settings other than DAs offices and women's shelters. The Institute of Medicine Committee Report titled Clinical Preventive Services for Women (Recommendation 5.7) ${ }^{43}$ recommendation that healthcare providers screen all women for interpersonal and domestic violence raises the issue of what to do when women screen positive for violence. The PTSD symptom predictor tool may help providers to determine who should be referred for intervention services, particularly mental health services.

Limitations include that the tool has only been tested in one population. There is a need for ongoing evaluation and possibly refinement of the tool. A second limitation is that a gold standard for measuring PTSD, such as the ClinicianAdministered PTSD Scale for DSM-5, ${ }^{44}$ was not used to measure PTSD. However the Post-Traumatic Stress Disorder 
Scale ${ }^{16}$ has been widely used and has established reliability and validity. Despite limitations, the tool provides researchers and front-line social and health professionals with a way to identify those at highest risk for sustained PTSD, as recommended by the NIMH workgroup ${ }^{1}$. It responds to Kessler et al.'s call to develop and test predictor tools in specific populations. ${ }^{14}$ Using this tool to identify mothers at high risk for sustained PTSD and entering them into intervention programs may protect mothers and children from negative outcomes and promote health and wellbeing. Recommendations for future research include evaluating the tool using a gold standard measure of PTSD and evaluating it in other populations.

To our knowledge, this is the first tool that predicts PTSD based on data collected when mothers first seek assistance. The predictors identified in the tool are consistent with risk factors for PTSD identified by experts in the NIMH workgroup $^{1}$ and others. For example, Ham-Rowbottom et al. and Kessler et al. also found that sustained PTSD was associated with a history of childhood abuse. ${ }^{6,14}$ Kessler et al. found that previous PTSD was associated with sustained PTSD following new trauma. ${ }^{14}$ The consistency with these research findings, and with others not alluded to for reasons of parsimony, adds to our confidence that this tool will be effective in identifying those most at risk for sustained PTSD. Additional strengths are that the tool was developed using longitudinal data and that it was tested over two time periods. Finally, this tool may contribute to the implementation of the Affordable Care Act requirement that free screening and brief counseling for partner violence be provided to women as part of preventive services. Miller et al. ${ }^{45}$ outline a systems approach to screening and counseling and identify the need for evidenceinformed IPV screening. Implementation of this tool may be one part of providing evidence-informed IPV screening in a cost effective manner that supports quality care. We hope that implementing the tool will result in mothers receiving needed services that improve their lives and the lives of their children.

\section{Acknowledgments}

This research was supported with funding from The Houston Endowment, and from Texas Woman's University Libraries' Open Access Fund. We appreciate the unflagging assistance and support of the administrators and staff of the five shelters in Harris County and the chief and staff of The Harris County District Attorney's Office, Family Criminal Law Division. The 300 women and children who allow us to record their pain and recovery take emotional risks each time we meet. As one woman said, "I want to talk but it hurts to remember." We thank each of the women who chose to remember and dedicate the findings of this research to their courage and determination.

\section{Author Disclosure Statement}

No competing financial interests exist.

\section{References}

1. National Institute of Mental Health. Post-traumatic stress disorder (PTSD) risk prediction, November 2, 2011. Available at: http://www.nimh.nih.gov/research-priorities/scientificmeetings/2011/post-traumatic-stress-disorder-ptsd-riskprediction/index.shtml. Accessed August 6, 2015.
2. Black MC, Basile KC, Breiding MJ, et al. The National Intimate Partner and Sexual Violence Survey (NISVS): 2010 summary report. Atlanta, GA: National Center for Injury Prevention and Control, Centers for Disease Control and Prevention, 2011.

3. World Health Organization (WHO). Global and regional estimates of violence against women: Prevalence and health effects of intimate partner violence and non-partner sexual violence. Geneva: WHO, 2013.

4. Johnson DM, Zlotnick C. Remission of PTSD after victims of intimate violence leave a shelter. J Trauma Stress 2012;25:203-206.

5. McFarlane J, Symes L, Maddoux J, Gilroy H, Koci A. Is shelter stay and receipt of a protection order associated with less violence and better functioning for abused women? Outcome data 4 months after receiving services. J Interpers Violence 2014;29:2748-2774.

6. Glass N, Perrin N, Campbell JC, Soeken K. The protective role of tangible support on post-traumatic stress disorder symptoms in urban women survivors of violence. Res Nurs Health 2007;30:558-568.

7. Ham-Rowbottom K A, Gordon E E, Jarvis K E, Novaco RW. Life constraints and psychological well-being of domestic violence shelter graduates. J Fam Violence 2005;20:109-121.

8. Koci A, McFarlane J, Cesario S, et al. Women's functioning following an intervention for partner violence: New knowledge for clinical practice from a seven year study. Issues Ment Health Nurs 2014;35:74-755.

9. McFarlane J, Symes L, Binder B, Maddoux J, Paulson R. Maternal-child dyads of functioning: The intergenerational impact of violence against women on children. Matern Child Health J 2014;182236-2243.

10. McFarlane J, Pennings J, Symes L, Maddoux J, Paulson R. Predicting abused women with children who return to the abuser: Development of a rapid assessment triage tool. J Threat Assess Manag 2014;1:274-290.

11. Panter-Brick C, Grimon MP, Eggerman M. Caregiver-child mental health: A prospective study in conflict and refugee settings. J Child Psychol Psychiatry 2014;55:313-327.

12. Enlow MB, Kitts RL, Blood E, Bizarro A, Hofmeister M, Wright RJ. Maternal posttraumatic stress symptoms and infant emotional reactivity and emotion regulation. Infant Behav Dev 2011;34:487-503.

13. Yehuda R, Bierer LM. (2008). Transgenerational transmission of cortisol and PTSD risk. Prog Brain Res 2008; 167:121-135.

14. Kessler RC, Rose S, Koenen KC, et al. How well can posttraumatic stress disorder be predicted from pre-trauma risk factors? An exploratory study in the WHO World Mental Health Surveys. World Psychiatry 2014;13:265-274.

15. McFarlane J, Nava A, Gilroy H, Paulson R, Maddoux J. Testing two global models to prevent violence against women and children: Methods and policy implications for a seven year prospective study. Issues Ment Health Nurs 2012;33:871-881.

16. Breslau N, Peterson E L, Kessler R C, Schultz LR. Short screening scale for DSM-IV posttraumatic stress disorder. Am J Psychiatry 1999;156:908-911.

17. Bohnert KM, Breslau N. Assessing the performance of the short screening scale for post-traumatic stress disorder in a large nationally representative survey. Int J Methods Psychiatr Res 2011;20:e1-e5.

18. McFarlane J, Parker B. Abuse during pregnancy: A protocol for prevention and intervention. White Plains, NY: March of Dimes, 1994. 
19. McFarlane J, Parker B, Cross B. Abuse during pregnancy: A protocol for prevention and intervention, 2nd ed. White Plains, NY: March of Dimes, 2001.

20. McFarlane J, Parker B, Morgan B. Abuse during pregnancy: A protocol for prevention and intervention, 3rd ed. White Plains, NY: March of Dimes, 2007.

21. McFarlane J, Malecha A, Gist J, et al. An intervention to increase safety behaviors of abused women: Results of a randomized clinical trial. Nurs Res 2002;51:347-354.

22. McFarlane J, Parker B, Soeken K, Silva C, Reel S. Safety behaviors of abused women after an intervention during pregnancy. J Obst GynecolNeonatal Nurs 1998;27:64-69.

23. Koci A. Marginality, abuse and adverse health outcomes in women. PhD dissertation. Emory University, Atlanta, GA, 2004.

24. Schwarzer R, Jerusalem M. Generalized self-efficacy scale. In: Weinman J, Wright S, Johnston M (eds). Measures in health psychology: A user's portfolio. Windsor, UK: NFER-NELSON, 1995:35-37.

25. Norbeck JS, Lindsey AM, Carrieri VL. The development of an instrument to measure social support. Nurs Res 1981;30:264-269.

26. Norbeck JS, Lindsey AM, Carrieri VL. Further development of the Norbeck Social Support Questionnaire: Normative data and validity testing. Nurs Res 1983;32:4-9.

27. Norbeck JS. Revised scoring instructions for the Norbeck Social Support Questionnaire (NSSQ). San Francisco: University of California, San Francisco: 1995 Available online at: www.nurseweb.ucsf.edu.

28. Campbell JC. Assessing dangerousness: Violence by sexual offenders, batters, and child abusers. Thousand Oaks, CA: Sage, 1995.

29. Campbell JC. Assessment of risk of homicide for battered women. ANS Adv Nurs Sci 1986;8:36-51.

30. Marshall L. Development of the Severity of Violence Against Women Scales. J Fam Violence 1992;7:103-121.

31. Coker AL, Smith PH, McKeown RE, King MJ. Frequency and correlates of intimate partner violence by type: Physical, sexual, and psychological battering. Am J Public Health 2000:90:553-559.

32. Gist J, McFarlane J, Malecha A, et al. Protection orders and assault charges: Do justice interventions Reduce violence against women? Am J Fam Law 2001;15:59-71.

33. Centers for Disease Control and Prevention (CDC). Behavioral Risk Factor Surveillance System survey questionnaire. Atlanta, GA: U.S. Department of Health and Human Services, CDC, 2009.

34. Centers for Disease Control and Prevention (CDC). Behavioral Risk Factor Surveillance System survey question- naire. Atlanta, GA: U.S. Department of Health and Human Services, CDC, 2010.

35. Meulman JJ, van der Kooij AJ, Heiser WJ. Principal components analysis with nonlinear optimal scaling transformations for ordinal and nominal data. In D. Kaplan, ed. Handbook of quantitative methodology for the social sciences. Thousand Oaks, CA: Sage Publications, Inc., 2004.

36. Moons K.G., Kengne AP, Woodward M, et al. Risk prediction models: Development, internal validation, and assessing the incremental value of a new (bio) marker. Heart 2012;98:683-690.

37. Steyerberg EW, Eijkemans MJ, Harrell FE, Habbema JD. Prognostic 9 modeling with logistic regression analysis: in search of a sensible strategy in small data sets. Med Decis Making 2001;21:45-56.

38. Sun GW, Shook TL, Kay G.L. Inappropriate use of bivariable analysis to 8 screen risk factors for use in multivariable analysis. J Clin Epidemiol 1996;49:907-916.

39. Tibshirani R. Regression shrinkage and selection via the lasso. J R Stati Soc Series B Methodol 1996: 267-288.

40. Janes H, Pepe MS, Gu W. Assessing the value of risk predictions by using risk stratification tables. Ann Intern Med 2008;149:751-760.

41. Skalská H, Freylich V. Web-bootstrap estimate of area under ROC curve. Austrian J Stat 2006;35:325-330.

42. Meulman JJ, Heiser WJ. IBM SPSS Categories 19. Chicago: IBM SPSS, Inc., 2012. www.sussex.ac.uk/its/pdfs/ SPSS_Categories_21.pdf.

43. Institute of Medicine (IOM). Clinical preventive services for women: Closing the gaps. Washington, DC: The National Academies Press, 2011.

44. Weathers FW, Blake DD, Schnurr PP, Kaloupek DG, Marx BP, Keane TM. Clinician-administered PTSD scale for DSM-5 (CAPS-5). National Center for PTSD, 2013. Available at: at www.ptsd.va.gov/professional/assessment/ adult-int/caps.asp. Accessed August 6, 2015.

45. Miller E, McCaw B, Humphreys BL, Mitchell C. Integrating intimate partner violence assessment and intervention into healthcare in the United States: A systems approach. J Womens Health 2015;24:92-99.

Address correspondence to:
Lene Symes, PhD
College of Nursing
Texas Woman's University
6700 Fannin Street
Houston, TX 77030

E-mail: 1symes@twu.edu 